\title{
New Frontiers in Gastroenterology: The 13th Annual Meeting of the Japanese Gastroenterological Association
}

The 13th Annual Meeting of the Japanese Gastroenterological Association (JGA) was organized by Prof. Takashi Joh of Nagoya City University and was held in Nagoya on February 17 and 18, 2017. During this conference, special lectures, educational lectures, core symposia, workshops, and one international session (IGICS) were held apart from general presentations.

Articles published in the present Digestion JGA Special Issue 2018 represent the best presentations from the 13th Annual Meeting. Chairpersons of the sessions and members of the editorial board have recommended numerous papers from their sections; subsequently, the editorial committee of the JGA has selected distinguished presentations from these recommendations and invited the authors to submit their papers for publication in this special issue. Four reviews and 7 original articles were accepted for final publication. All manuscripts were independently reviewed by 2 members of the JGA editorial committee.

\section{Summaries of 2 Core Symposia in JGA 2015-2017}

The scientific organizing committee selected serial topics for the core symposium. In this special issue, chairpersons of these sessions have provided summaries on the topics, "New medical approach to functional dyspepsia" and "Interaction between medical treatment and minimally invasive surgical treatment for the malignancies of the digestive tract".

\section{Selected Distinguished Papers}

Under the broad category of diagnosis and treatment of gastrointestinal malignant lesions, 3 articles described the validity of minimally invasive salvage operations, the efficacy of imatinib mesylate against advanced or recurrent GIST, and the correlation between LINE-1 methylation and its prognostic impact on GI cancers.

In the field of acid-related diseases, 2 articles described a new method of the functional examination using endoscopy-guided real-time measurement and hypergastrinemia caused by a novel potassium-competitive acid blocker, vonoprazan.

In regard to advances in endoscopic technology for the diagnosis and treatment of gastrointestinal cancers, 3 articles described endoscopic treatment for adenocarcinoma of the esophagogastric junction, superficial non-ampullary duodenal epithelial tumors, and colorectal polyps. One article reviewed the clinical utility of capsule endoscopy and double-balloon enteroscopy in the management of obscure gastrointestinal bleeding.

In topics on ulcerative colitis, 3 articles described ulcerative proctitis, fecal markers in patients with ulcerative colitis, and tacrolimus for refractory ulcerative colitis.

We believe that this issue will provide useful information to clinicians and investigators. We wish to express our sincere gratitude to all the authors, chairpersons, and editorial board members for their contributions to this special issue.

\author{
Koji Yakabi, MD, PhD \\ Kazuhide Higuchi, $M D, P h D$ \\ Co-editors of the JGA Editorial Committee
}

